Vol. 21, no.4, 2020

\title{
sciendo
}

Transport and Telecommunication, 2020, volume 21, no. 4, 275-284

Transport and Telecommunication Institute, Lomonosova 1, Riga, LV-1019, Latvia

DOI $10.2478 / \mathrm{ttj}-2020-0022$

\section{ON TRANSPORT MONITORING AND FORECASTING DURING COVID-19 PANDEMIC IN ROME}

\author{
Stefano Brinchi ${ }^{1}$, Stefano Carrese ${ }^{2}$, Ernesto Cipriani ${ }^{2}$, Chiara Colombaroni, \\ Umberto Crisalli, Gaetano Fusco ${ }^{3}$, Andrea Gemma ${ }^{2}$, Natalia Isaenko ${ }^{3}$, Livia \\ Mannini ${ }^{2}$, Sergio Maria Patella ${ }^{5}$, Marco Petrelli ${ }^{2}$ \\ ${ }^{1}$ Rome Mobility Agency (Roma Servizi per la Mobilità) \\ Via L. Gaurico 9, 00143 Rome, Italy \\ stefano.brinchi@romamobilita.it \\ ${ }_{2}^{2}$ Department of Engineering, Roma Tre University \\ Via Vito Volterra 62, 00146 Rome, Italy \\ stefano.carrese@uniroma3.it,ernesto.cipriani@uniroma3.it,andrea.gemma@uniroma3.it, \\ livia.mannini@uniroma3.it,marco.petrelli@uniroma3.it \\ ${ }^{3}$ DICEA, Sapienza University of Rome \\ Via Eudossiana 18, 00184 Rome, Italy \\ chiara.colombaroni@uniroma1.it,gaetano.fusco@uniroma1.it,natalia.isaenko@uniroma1.it \\ ${ }^{4}$ Department of Enterprise Engineering, Tor Vergata University of Rome \\ Via del Politecnico 1, 00133 Rome, Italy \\ crisalli@ing.uniroma2.it \\ ${ }^{5}$ Faculty of Economics, University Mercatorum \\ Piazza Mattei 10,00186 Rome, Italy \\ sergiomaria.patella@unimercatorum.it
}

\begin{abstract}
This paper presents the results of a study on the Rome mobility system aiming at estimating the impacts of the progressive lockdown, imposed by the government, due to the Covid-19 pandemic as well as to support decision makers in planning the transport system for the restart towards a post-Covid "new normal". The analysis of data obtained by the transport monitoring system has been fundamental for both investigating effects of the lockdown and feeding transport models to predict the impacts on future actions. At first, the paper focuses on the so-called transport analytics, by describing mobility trends for the multimodal transportation system of Rome. Then, the results of the simulated scenarios to design public transport services, able to ensure passengers social distancing required in the first post-Covid months, are presented and discussed.
\end{abstract}

Keywords: Covid-19, transport analytics, transport monitoring, transport modelling, predictions.

\section{Introduction}

The Covid-19 emergency has been an incredible challenge for all mankind, not only from a healthy point of view, but also from a socio-economic point of view, in which a reliable and sustainable transport of people and goods is crucial. The progressive shutdown of non-essential activities, personal isolation and social distancing are extreme "lockdown" measures that impact considerably on social and economic patterns of involved communities with catastrophic effects similar to wars. In this period, monitoring people movements is fundamental to prevent the virus spreading as well as is important to analyse the mobility patterns, which results significantly modified in all the travel dimensions: the spatial and temporal distribution, the mode choice and the route one.

Today, researchers are asked to recompose the 'puzzle' of the activities, by including transport mobility ones, and to recalibrate their models and tools to support the design and management of transport systems to be ready for the post-Covid era that, at first, is including the respect of the limits imposed by healthy requirements and technical constraints of the transport system. 
This paper reports some of the results obtained by a working group, which includes the authors, aiming at supporting the Rome Mobility Agency (Roma Servizi per la Mobilità, 2020) to:

- analyse the Rome mobility system and estimate the impacts of the progressive lockdown imposed by the government;

- plan the reboot of the mobility system by calibrating and applying transport simulation models to design, for example, public transport services able to ensure passengers social distancing required in the first post-Covid months.

This study arises from the consideration that the major data providers are supplying reports that illustrate data analytics on people's mobility in most Countries, regions and even towns in the world (Apple, Mobility Trends Reports, 2020; Google, COVID-19 Community Mobility Reports, 2020; Moovit, Impact of Coronavirus (COVID-19) on Public Transit usage, 2020; TomTom, COVID-19 Update, 2020). Unfortunately, they do not provide the higher resolution level required to analyse the mobility within cities, and specific investigations are needed. For this reason, this paper presents an analysis of mobility data at the traffic zoning level (more than 1300 traffic zones) adopted in the modelling system of Rome Mobility Agency (RSM), aiming at exploring lockdown trip mobility patterns among traffic zones of the metropolitan area of Rome. Thanks to the detailed data provided by RSM, such a time-spatial representation enables the application of decision support systems to predict the impacts of future actions on the post-Covid mobility, that has been carried out by a massive use of simulated scenarios by using transport models. As Covid-19 pandemic is still present, this study is continuously "in-progress" since emergency started.

The paper is structured as follows: section 2 describes the study area and its transport network, by including the traffic monitoring system; section 3 summarizes the important dates of Covid-19 pandemic in Rome; section 4 presents the results of monitoring for both road and public transport; section 5 describes the system of models and some application results for planning the reboot of the mobility system in Rome. Finally, section 6 reports the discussion and conclusions of this study.

\section{The study area}

The study area is the Metropolitan Area of Rome, which is made of two macro-areas: the urban area of the Municipality of Rome $\left(1,285 \mathrm{~km}^{2}\right.$ and 2.9 million inhabitants) and the rest of its province $\left(4,065 \mathrm{~km}^{2}\right.$ and 1.7 million inhabitants). Overall, the study area consists of a population of about 4.6 million of inhabitants living in about $5,350 \mathrm{~km}^{2}$. This area is served by $8,000 \mathrm{~km}$ of the existing roads. The main road network extends to about $400 \mathrm{~km}$ where $50 \%$ of the traffic passes and the $30 \%$ of accidents in Rome occur; the largest part of such a network $(300 \mathrm{~km})$ is within the "Grande Raccordo Anulare" (GRA), a circular freeway approximately $68 \mathrm{~km}$ long (see Fig. 1a) that separates the city centre from its suburbs. Focusing on the urban area, the transit system is based on a radial metro network (3 lines), which extends for a total of about $60 \mathrm{~km}$, currently with two interchanges in the city centre (Termini rail station and San Giovanni metro station). The urban mass system is integrated with tram and bus networks providing an extensive and widespread coverage of the service thanks to more than 350 lines. Then, 7 railway lines connect the surrounding suburban areas to the city centre: five of these railway lines create a half circle inside the GRA known as the "rail ring", as pictured in Fig. 1b.

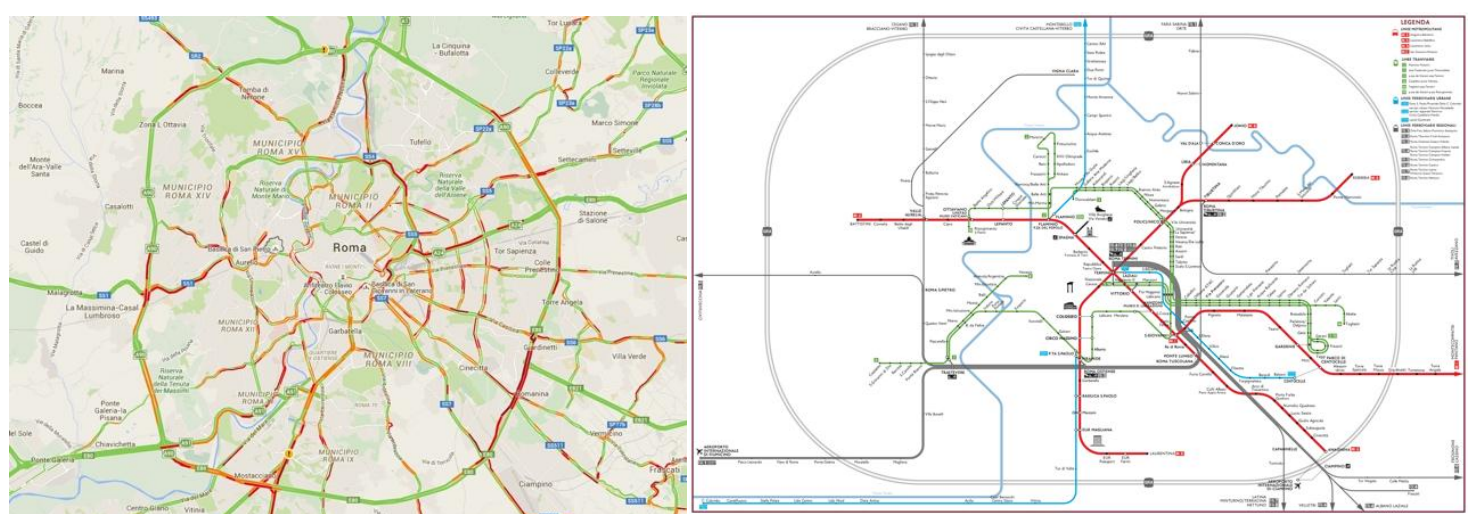

(a) road network

(b) public transport

Figure 1. The transport system of Rome 
The above transport network is monitored by the Control Mobility Centre of the Rome Mobility Agency aiming at managing and controlling the urban traffic.

The Agency uses various types of sensors both traditional and innovative, which can be summarized as follows: electromagnetic loops; gates of limited traffic zones; Floating Car Data (FCD), i.e. GPS positions and speeds of cars and heavy vehicles, that allow study travel time (Cipriani et al., 2014), parking search time (Mannini et al., 2017) or calibration of models to forecast network congestion (Fusco et al., 2013); Bluetooth and WiFi data (Carrese et al., 2020); turnstiles data; AVL (Automatic Vehicle Location) data of public transport vehicles; traffic video cameras; integrated accident recording system; crowdsourced traffic reports. Such technologies feed the OpenData webservices available on the Agency website (Roma Servizi per la Mobilità, 2020), where data related to the public transport are also treated; they can be used to disseminate user information (Nuzzolo et al., 2013) or to feed predictions (Nuzzolo et al., 2015).

The most relevant data reported above have been used to estimate the impacts of Covid-19 on the mobility of Metropolitan Area of Rome. The results of the analysis of such data produced the Transport Analytics presented in the following Section 4. Weekly updates of such data can be found in (Rome Mobility Agency (Roma Servizi per la Mobilità), Covid 19: impatto sulla mobilità, 2020).

On the transport demand side, the morning peak hour of a pre-Covid pandemic workday is characterised by a total of 743 thousand trips of which, more than $50 \%$ (about 550,000) are within the city. It is worth noting that while the use of private vehicles is higher in the most peripheral areas $(72 \%$ of the overall demand), the opposite happens for public transport, which presents a low usage rate in the outermost areas (25-26\% of modal choices) and increases in the most central area (about the $32 \%$ ).

\section{Covid-19 pandemic milestones in Rome}

The progressive lockdown imposed by the government authorities (national, regional and local) as well as the main milestones for the restart towards the "new" normal are briefly described in Tab. 1. The reader should note that this table reports only information impacting on the Rome mobility system, which the following analysis focused on. The imposed Italian-style prohibitions on everyone leaving their homes can be seen in Fig. 2. This figure shows the percentage variation of the mobility (number of trips) for different players (workers and students) at the different lockdown milestones (L0, L1, L2, L3, L4) w.r.t. the pre-Covid scenario, which influence both the trip generation and the trip distribution according to the imposed limitations pointed out in Fig. 2. Such a mobility refers to different demand segments representing students and workers in the different sectors, e.g. Workers in "essential" or "non-essential" activities (see Tab. 1) or smart-workers.

Table 1. Covid-19 lockdown timeline in Rome

\begin{tabular}{|c|c|c|}
\hline level & date & shutdown description \\
\hline L0 & $23^{\text {th }}$ February 2020 & $\begin{array}{l}\text { Strict quarantine (red zones) imposed in towns of northern regions. Travelling to the } \\
\text { north regions is not recommended. }\end{array}$ \\
\hline L1 & $4^{\text {th }}$ March 2020 & $\begin{array}{l}\text { schools are closed while universities open for research purposes only. Social distancing } \\
\text { in crowded places is recommended. }\end{array}$ \\
\hline L2 & 11th March 2020 & $\begin{array}{l}\text { Bars, restaurants and public food courts are closed. Refraining from unnecessary travel is } \\
\text { recommended. Social distancing is mandatory. Working remotely is highly suggested, } \\
\text { except for unavoidable services. Limited Traffic Zones are disabled (all traffic allowed in } \\
\text { the city center). }\end{array}$ \\
\hline L3 & $13^{\text {th }}$ March 2020 & $\begin{array}{l}\text { All public parks and gardens are closed. No outdoor sport activities allowed. Residents } \\
\text { can walk their dogs only nearby home. Stay home is imposed except for unavoidable } \\
\text { needs. }\end{array}$ \\
\hline L4 & $22^{\text {th }}$ March 2020 & $\begin{array}{l}\text { All "non-essential" shops and activities are closed. Food and drink retailers, banks, } \\
\text { chemists, petrol stations, newsagents, as well as other particular categories defined } \\
\text { "essential" to support coronavirus emergency are exempted from the ban. Residents } \\
\text { are still allowed to shop for food, to go to work (if their job belongs to "essential" } \\
\text { categories and it is impossible to do remotely) or to move for unavoidable needs (e.g. } \\
\text { support to elderly who are not self-sufficient). }\end{array}$ \\
\hline $\mathrm{R} 1$ & $4^{\text {th }}$ May 2020 & $\begin{array}{l}\text { All "non-essential" shops and activities reopening. Go to work is allowed even if } \\
\text { smart-working is still recommended. No more "stay home" rule applies. Outdoor sport } \\
\text { activities allowed. With the exception of family, social distancing is required. }\end{array}$ \\
\hline R2 & $18^{\text {th }}$ May 2020 & $\begin{array}{l}\text { All retail, recreation, bars, restaurants and public food courts reopening. Go to work is } \\
\text { allowed but again smart-working is recommended. Public parks open even if social } \\
\text { distancing still apply. Schools and universities remain closed. }\end{array}$ \\
\hline
\end{tabular}

The pre-Covid scenario, below assumed as the reference one, is set to the average mobility levels and features measured in the workdays of the first two weeks of February 2020. The impact of the different lockdown milestones can be summarized as follows: in L0 all intercity trips (mainly involving national railway stations and Rome airports) are importantly downsized; in L1 study trips miss; in L2 
retail and recreational trips switched off; in L3 the mobility for sports and leisure is forbidden; in L4 only unavoidable trips are allowed. Then, looking at the progressive restart of Rome activities, we can point out at the beginning of May where in R1 the "stay home" rule is cancelled, all "non-essential" shops and activities reopen, smart-working is still recommended and outdoor sport activities are allowed. After two weeks, aiming at consolidating the restart of R1, in $\mathrm{R} 2$ all retail, recreation, bars, restaurants and public parks reopen although social distancing still applies. Given the pre-Covid milestone as reference, Fig. 2 also shows the effects of the restrictions and reboots on the different demand segments related to people activities. The results in terms of mobility monitoring is presented in the following section 4 .

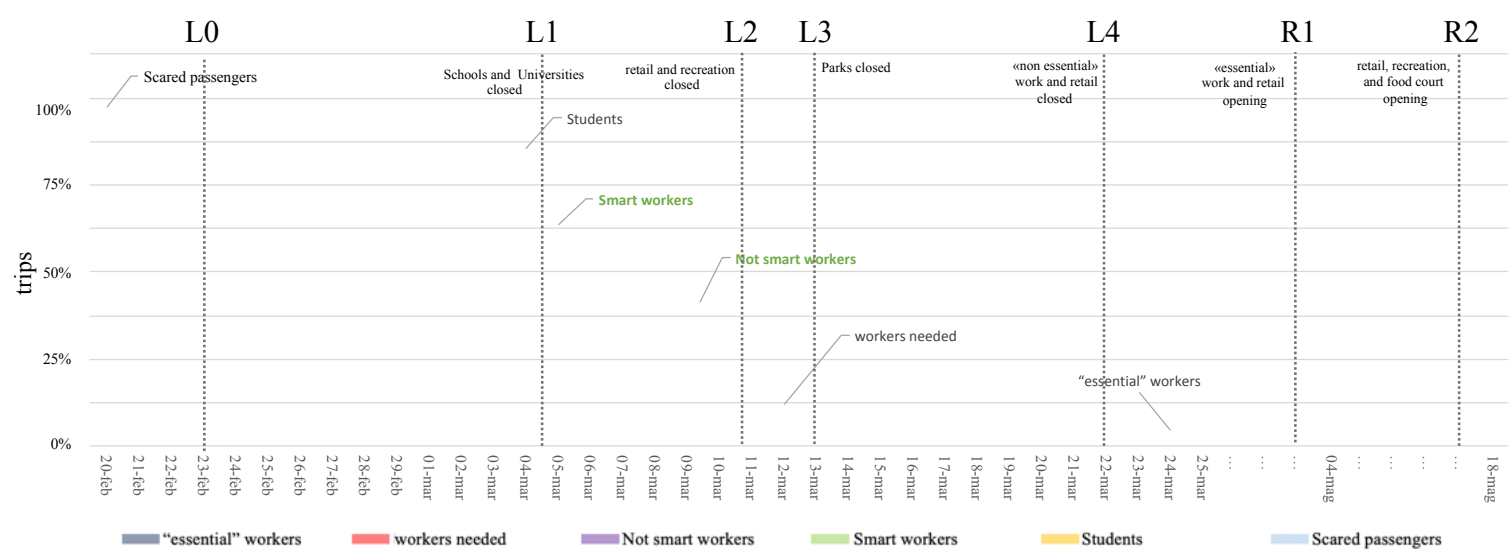

L0, L1,L2,L3,L4 lockdown milestones $\quad$ R1, R2 reboot milestones

Figure 2. Covid-19 pandemic milestones and mobility players

\section{Monitoring the mobility system lockdown}

This section describes the results of the monitoring of the Rome mobility system during the lockdown imposed by the government as described in Tab. 1. In the following the analysis of the socalled transport analytics is presented for both the road network and the public transport one.

\subsection{Road network}

The analysis of road traffic can be done by the percentage variations of cars and heavy vehicles resulting from FCD. Such variations are calculated w.r.t. the pre-Covid scenario.

Fig. 3 does not present significant differences when quarantine has been imposed in northern towns of Italy (L0). It is the same for heavy traffic in L1 milestone, while a reduction for cars can be seen due to the shutdown of schools and universities. Cars and heavy vehicles present considerable reductions with the adoption of social distancing and remote working measures (L2), although heavy traffic reduces less because it represents the backbone of freight and logistic supply for foodstuff. As L3 (parks closure) is mainly oriented to pedestrians, reductions do not affect vehicles. The adoption of L4 restrictive measures base on the "stay home" rule implies biggest reductions w.r.t. the pre-Covid for both traffic categories.

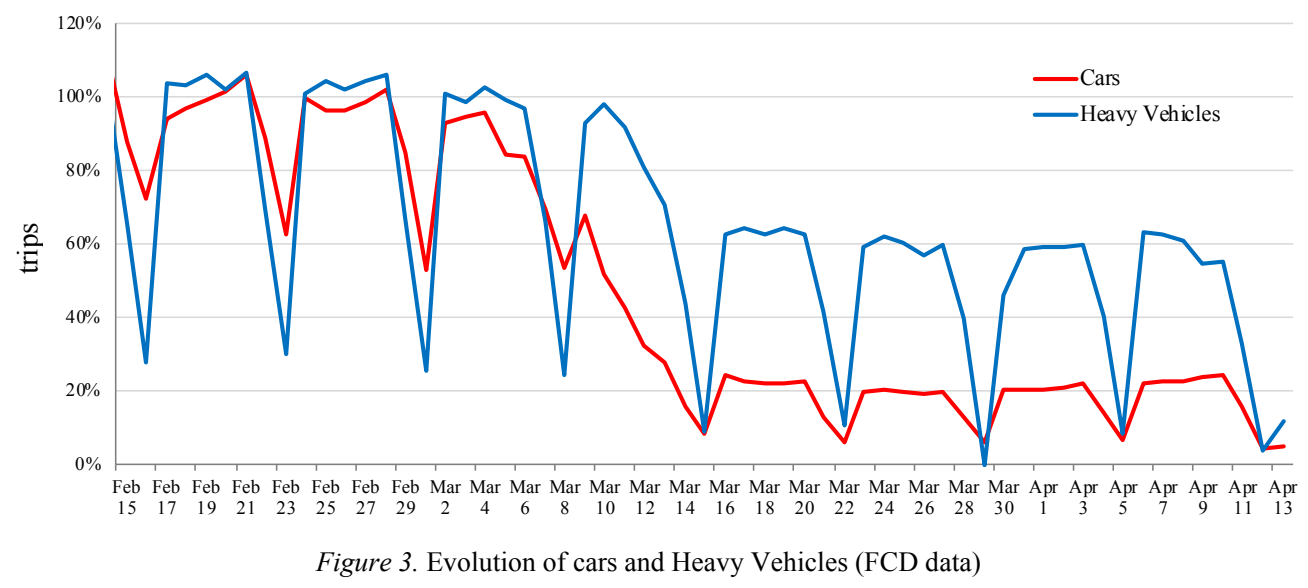


The FCD are a sample of the entire traffic, and if we look at absolute values of traffic flows (universe) we need to analyse data of fixed stations located on the road network. Such data are detected by video cameras located in the city center, for which the percentage reduction of traffic volumes per vehicle type (Motorcycles, Cars, Light and Heavy Vehicles) is shown in Fig. 4. This figure shows the decrease of the different vehicle classes monitored at different lockdown milestones. In particular, Cars and Light Vehicles exhibit a very similar trend, with no significant decline until L1 and progressive reductions as $30 \%$ on $\mathrm{L} 2,60 \%$ on L3, up to $78 \%$ on average in the workdays after L4. Motorcycle traffic shows a similar trend until L3 and a wider reduction of more than $80 \%$ after L4. A very different trend can be seen for Heavy Vehicles, which are not directly affected by the restrictions addressed to people, but are due to the progressive closure of shops and work places. Indeed, heavy traffic reduction in L2 is only the $20 \%$; this value decreases to the $35 \%$ in L3, and then reach about the $50 \%$ in L 4 and later on during the lockdown.

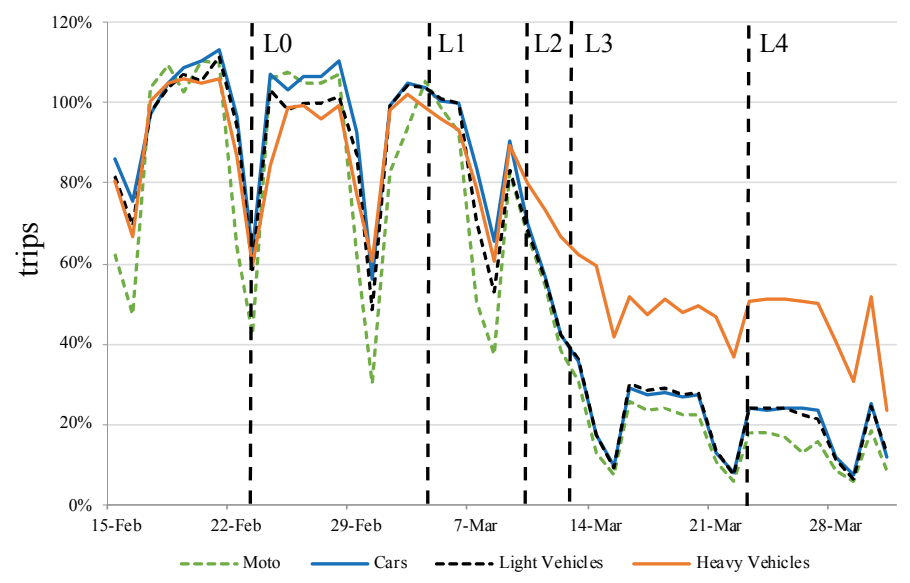

Figure 4. Traffic detected at fixed stations

By deepening on pedestrian traffic, Fig. 5 illustrates results of data coming from Bluetooth sensors, which shows a similar trend of variation as in the previous analyses. In particular, increasing reductions are detected both in L1 (30\%) and in L2 (55\%) milestones. L3 ban is particularly focused on pedestrians as shown by the large reduction of the $82 \%$, which is extremely wider if compared with the value of the same day of the previous week (falling in L1) when the reduction was only the $30 \%$. The adoption of the most restrictive measures of L4 reflects in the maximum reduction of pedestrian movements (more than 90\%). A similar trend and corresponding reductions can be seen for bikes.

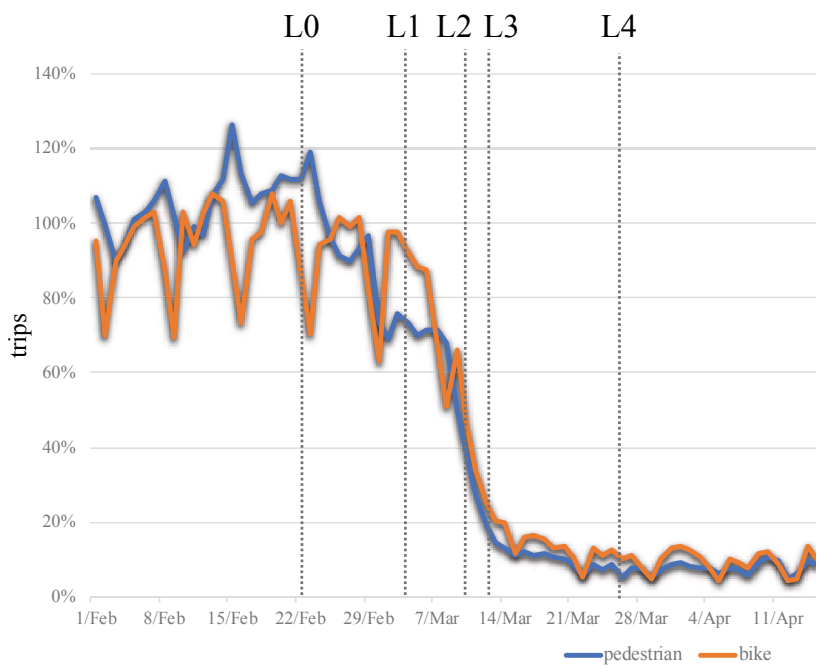

L0, L1,L2,L3,L4 lockdown milestones

Figure 5. Pedestrian and bike traffic during the lockdown (Bluetooth data) 


\subsection{Public transport}

Passenger trends on the three metro lines (A, B, and C) and their extensions (B1 and Lido), again compared to the average values observed in the working days of the first two weeks of February, is reported in Fig. 6. The lines that cross the central area of the town and connect opposite semi-peripheral areas (A, B, and B1) show very similar trends and have the highest reductions of passengers with respect to the reference (pre-Covid): $22 \%$ on L2; $10 \%$ on L3, and $5 \%$ on average in the workdays after L4. Minor reductions are observed on the $\mathrm{C}$ and Lido lines that connect the City center with the most external areas of the metropolitan area: $37 \%, 21 \%$, and $12 \%$ on $\mathrm{C}$ line and $27 \%, 14 \%$, and $7 \%$ on Lido line, respectively on L2, L3, L4 and later on.

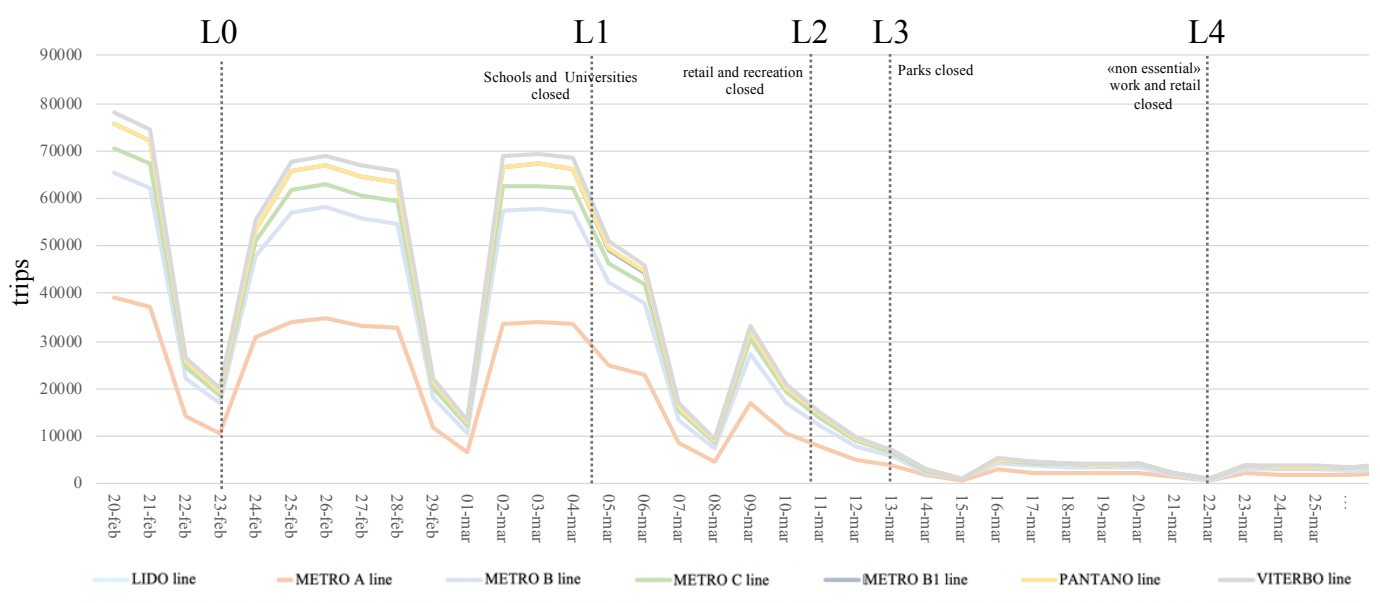

L0, L1,L2,L3,L4 lockdown milestones

Figure 6. Evolution of the number of passengers in the metro lines of Rome

\section{Planning the mobility system reboot}

The system of transport models used for simulating the mobility of Rome is based on a wellconsolidated set of models, which has been adapted to reproduce user choices in the Covid-19 pandemic.

The system functional architecture of the modelling is shown in Fig. 7, which allows to simulate the traffic of passengers and freight on the road network as well as the passengers on the public transport. The simulation aims at reproducing the interaction between demand and supply for a given scenario (e.g day $\mathrm{X}$ ) by using as input socio-economic data and transport networks.

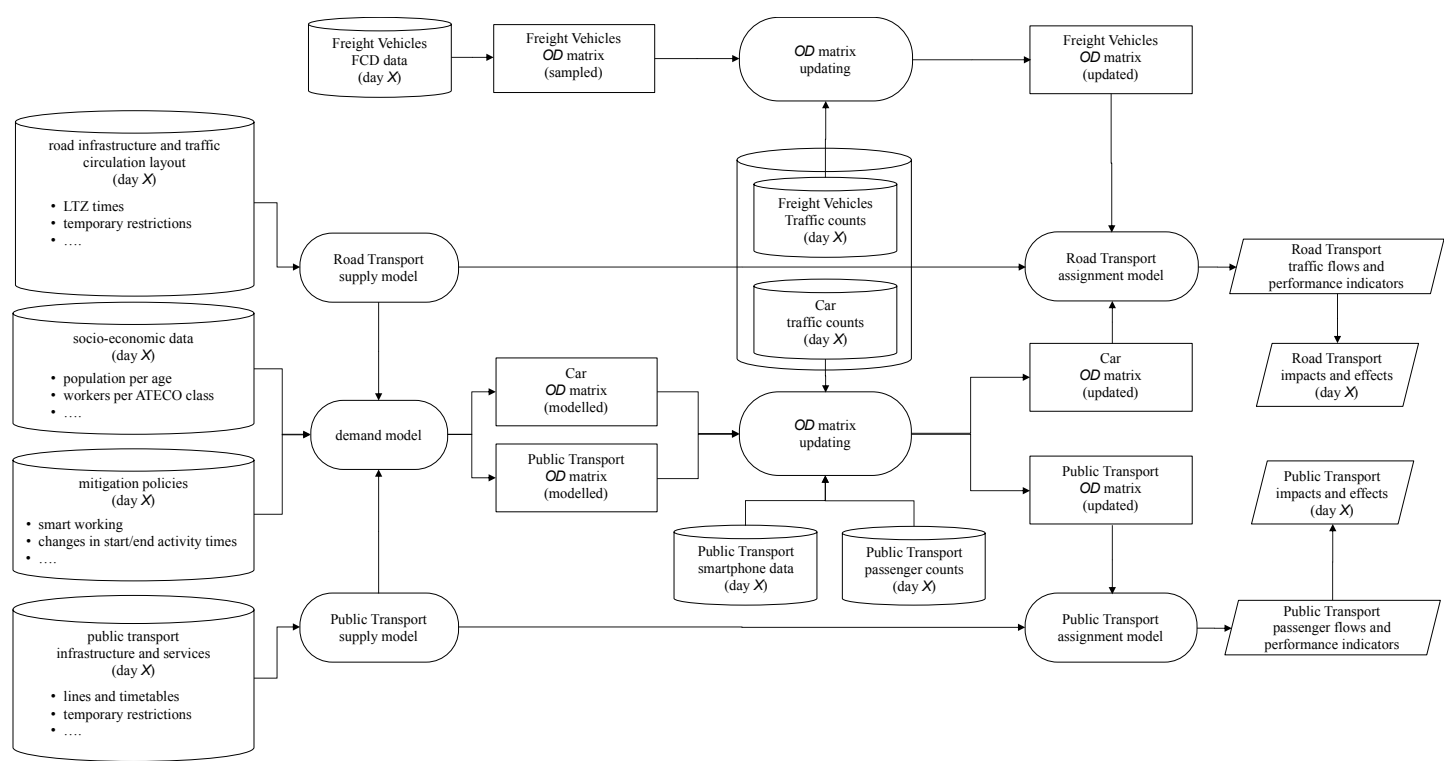

Figure 7. Transport models 
The modelling system has been adapted to capture changes in transport network usage and performances related to the application of policies to flatten the demand curve such as the application of smart-working to commuters (i.e. massive working at home) or the change in opening and/or closing times of shops, commercial activities, food courts and similar. By focusing on the single model components, the multimodal transport network is represented by two different supply models: the former aims at reproducing the road network usage and performances for private transport (passenger cars and freight vehicles); the latter allows to represent the public transport (regional trains, metro, tram and bus lines) modelled by using a line-approach with associated service frequencies. Origin-Destination (OD) passenger trips for the simulated scenario are estimated by using multi-step demand models based on a system of generation, distribution and modal choice models. They take into account four different trip purposes (work, school, university and others) and four mode alternatives (pedestrian, motorbike, private car and public transport). Then, freight OD trips are obtained by an initial sampled OD matrix, which is currently updated by traffic counts.

The OD matrices per mode carried out by using such model system are updated by using all traffic data available, including Floating Car Data, smartphone data and metro counts at entering gates.

In order to improve the quality of demand estimates for never-proven scenarios (i.e. Covid-19 pandemic), a further adjustment by using a "pivot" technique is used. Such a technique "locks" the demand prediction of a scenario in the Covid era (C) to the one carried out by models calibrated for the pre-Covid (P) scenario. Given the OD pair od, the pivoting is applied as follows:

$$
d_{o d}^{C}=d_{o d}^{P} * \frac{M P_{o d}^{C}}{M P_{o d}^{P}}
$$

where: $d_{o d}^{C}$ is the pivoting result, i.e. the demand estimated for the Covid scenario $(\mathrm{C}) ; d_{o d}^{P}$ is the preCovid (P) demand; $M P_{o d}^{C}$ is the demand estimated by applying the demand model to the Covid (C) scenario; $M P_{o d}^{P}$ is the demand estimated by applying the demand model to the pre-Covid (P) scenario.

The assignment of the pivoted OD matrices per mode to the transport networks is based on a static approach by using an equilibrium formulation. The demand-supply interaction is simulated by using stochastic path choice models for the road assignment and by using the hyperpath choice model for public transport. Assignment results concern traffic flows and network performances, as well as passengers boarding public transport lines. They are used to calculate performance indicators useful for the assessment and the design, as described below.

The system of transport models has been used to support decision makers in defining actions for a safe restart of the activities towards the "new normal" post-Covid in Rome. In particular, two different reboot scenarios are here presented: they refer to the Reboot 1 (R1) and Reboot 2 (R2) illustrated in Tab. 1. Even if the simulation involves all the multimodal transport system (private and public transport), results are here presented in terms of on-board flows on Metro lines as they represent the major critical point of the entire transport network as to assure the social distance imposed by the government due to Covid-19.

By focusing on the R1 scenario, Fig. 8 represents the on-board passengers for each section of the most crowded line (Metro A from Anagnina to Battistini). Such a value is compared with the maximum passenger allowed of 200 pass/train, which reflects the limit of 1-meter distancing between passengers imposed by the government, and with the load of the pre-Covid period.

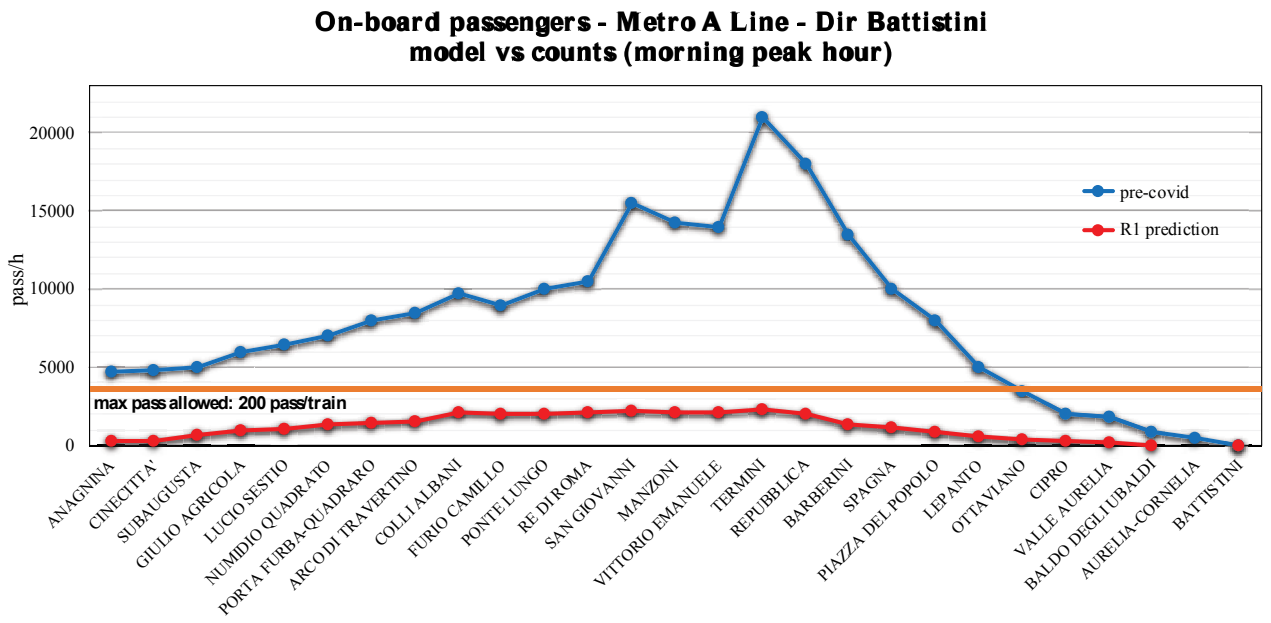

Figure 8. On-board flow prediction - Metro A Line in the morning peak hour (scenario R1) 
As we can see, the maximum load (about 2300 pass/h) in the morning peak hour is expected when arriving at Termini station (Rome city centre); it is quite far from the maximum allowed and it does not enable particular warnings to treat but it is dramatically lower w.r.t. the pre-Covid period (about 21000 pass $/ \mathrm{h}$ ) . This result reflects the pandemic effects on public transport ridership as the result of flattening the demand curve by applying smart-working policies as well as the large model split towards the private transport for a safer trip. This scenario presents a public transport share of about $10 \%$ w.r.t. the average of the $30 \%$ of the pre-Covid period.

In order to prove the modelling system capability to reproduce passenger flows in a neverexperimented environment as the Covid-19 pandemic one, model output has been validated by an ex-post comparison of on-board flow predictions with passenger counts. They have been acquired for the same simulated day (i.e. 4th May 2020). Fig. 9 shows results of the comparison for the Metro line of Fig. 8. As we can see, model fits very well counts as shown by the R1 very close to one, although it is possible to highlight a slight overestimation of the model, which is probably due to a slight optimistic usage of the public transport resulting from the modal split. The magnitude of this approximation can be seen by the angular coefficient of the regression curve, which is slightly higher than one.

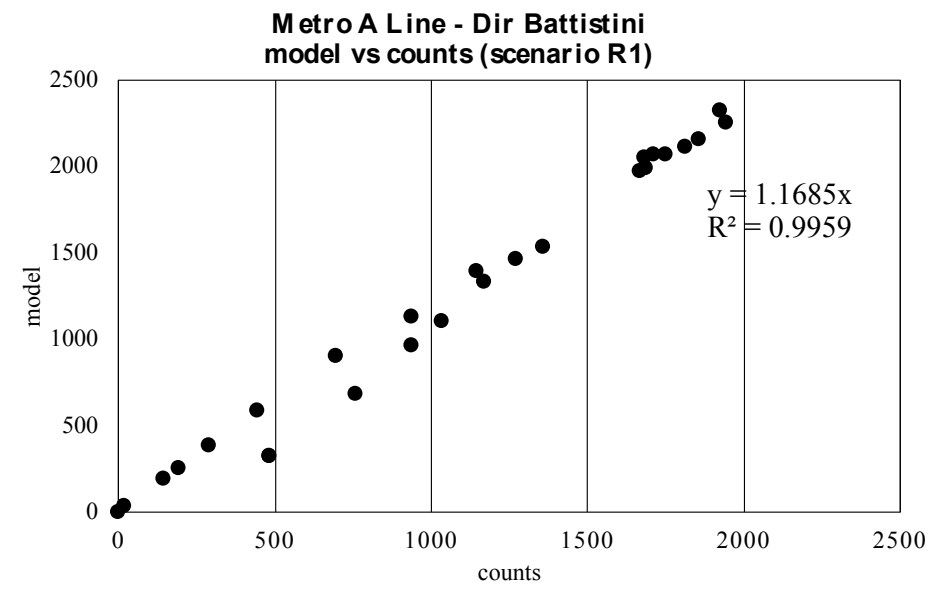

Figure 9. Model validation (scenario R1)

The very promising results obtained for the R1 scenario encouraged to provide forecasts for a set of short, mid and long term rebooting scenarios. As an example, predictions for the R2 scenario are here briefly described in terms of results for the same Metro line described in R1 (see Fig. 10). As expected, the progressive reopening of all activities that has an impact in the morning peak hour (only schools and universities remain closed) produces an increase of on-board flows. Even if this increase is very far from the pre-Covid period, it is estimated in about $5000 \mathrm{pass} / \mathrm{h}$ on the most crowded sections: the one arriving in San Giovanni station (interchange with the Metro $\mathrm{C}$ line) and the one arriving in Termini (the backbone of the public transport system in the center of Rome).

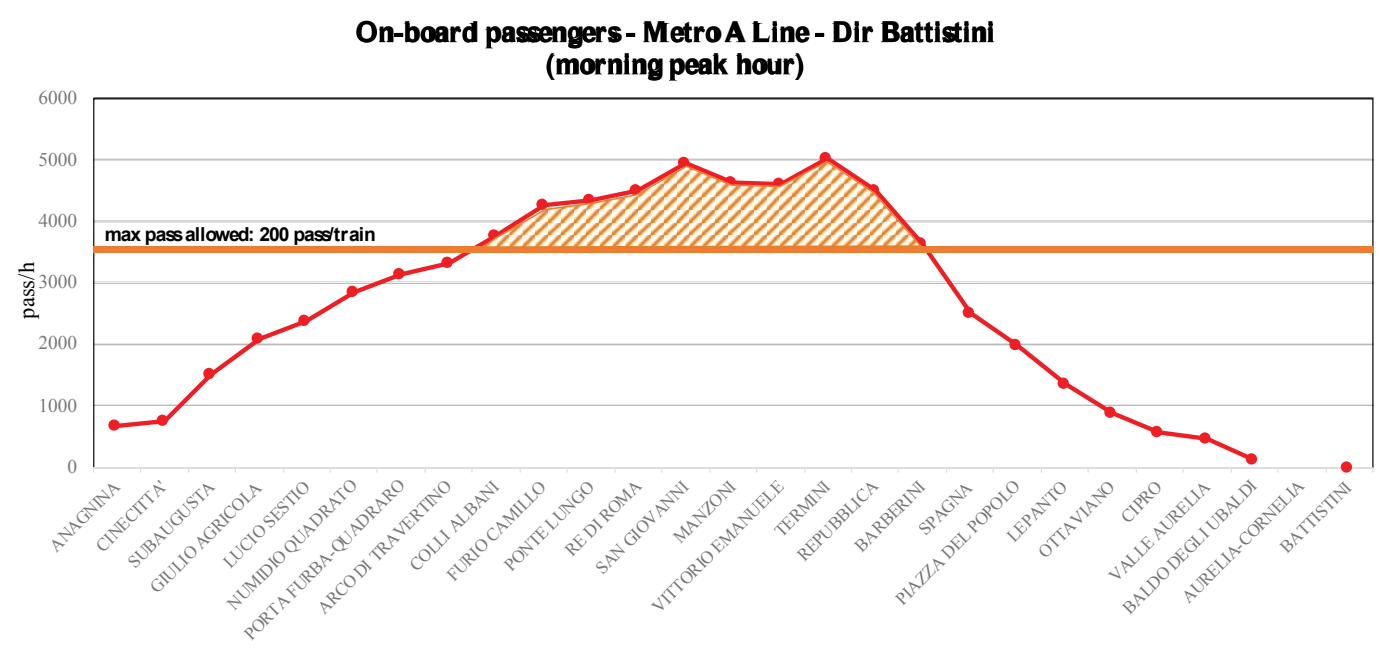

Figure 10. On-board flow prediction - Metro A Line in the morning peak hour (scenario R2) 
Estimated flows are very far from the line capacity (more than 20000 pass $/ \mathrm{h}$ ) of the ordinary days but they do not fit with distancing rules imposed by the government, as clearly illustrated in Fig. 10. In fact, such a figure clearly demonstrates that an important part of the line is characterised by on-board flows that exceed the maximum allowed due to the safety distance imposed by Covid-19 restriction. This problem arises from Colli Albani to Barberini, which is the part of line A that serves the inner part of the city, including city center. This result requires thinking about mitigation actions to reduce the on-board peaks up to allowed values.

\section{Discussion and conclusions}

The summary of monitoring results is reported in Fig. 11, which compares percentage variations of L4, R1 and R2 w.r.t. pre-Covid on the multimodal system of Rome.

As we can see, road traffic is rapidly covering the gap with pre-Covid: up to R2 only the $26 \%$ of cars and the $19 \%$ of trucks are missing; considering the positive trend of traffic increasing, congestion is expected to occur in a near future.

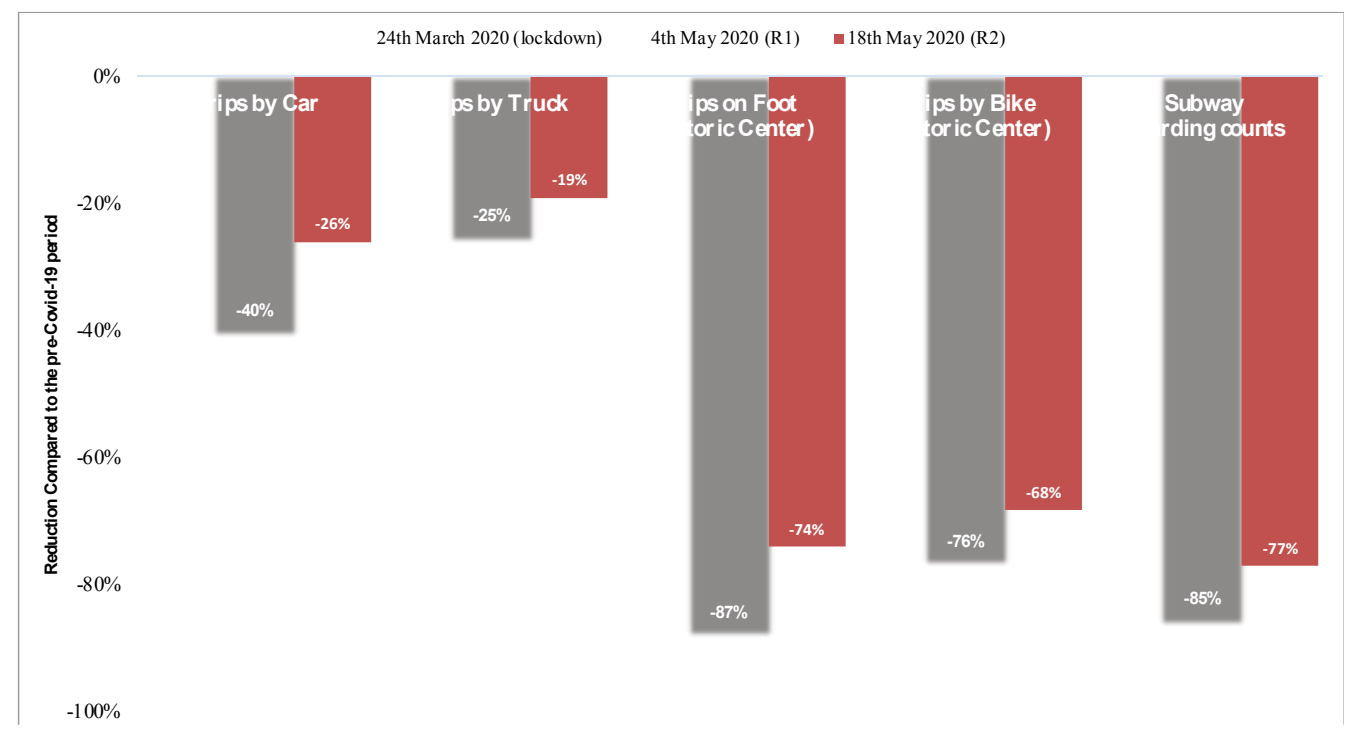

Figure 11. Summary of monitoring results on the Rome multimodal system

Unfortunately, the same rapidly increasing trend cannot be seen for public transport. Up to midMay (R2 scenario), the $77 \%$ of passengers are still missing. They reflect the absence of tourists and students as well as the presence of people that does not own a car for trips. In fact, in this period all LTZ (Limited Traffic Zone) of Rome are open to the whole traffic and people is allowed to reach the city center by car; the (low) parking fares usually are not a problem in Rome and the problem of park availability can be easily solved by anticipating the departure time, which has the further advantage of avoiding congestion.

Focusing on people moving in the city center, trips on foot as well as those by bike are still very far from the pre-Covid. As shown in Fig. 11, starting from the complete closure imposed by the lockdown (more than $90 \%$ of reduction), in mid-May we can see that about the $70 \%$ of the traffic is still missing as it is mainly related to tourism and recreational activities.

This lack is structural because this kind of mobility is strictly related to the restrictions on worldwide movements and the closure of national borders. Anyway, the reboot values registered in R1 and R2 indicate positive increasing trends.

The use of transport models to support the restart of the activities towards a progressive future "new normal" allowed to verify the robustness of the system of models used for decades in Rome, even if it is used to simulate never-experimented user behaviours due to travel during the pandemic days.

Predictions allowed to support decision makers in planning the reboot of the mobility system according safety rules imposed by the government.

For example, the oversaturation predicted in R2 on the metro line of Fig. 10 has been an important information for decision makers who were asked to think about appropriate measures to flatten the demand curve and to reduce the on-board peaks up to allowed values. 
This resulted in the design of a reinforcement of Metro services by using dedicated shuttle coaches. It consists of 70 coaches serving 6 lines following the same path of metro lines and/or connecting strategic points of the public transport system. In order to foster the competition with metro lines, the shuttle bus services have been designed to serve only the most important stations (head and interchange stations as well as park-and-ride ones). The reader should consider that in the simulated R2 scenario the road network is still far from congestion and bus travel times are comparable with metro ones between served station. This new temporary service is accompanied by a strong communication campaign carried out directly on-site at terminals aiming at modifying passenger choices from boarding the metro to boarding the shuttle bus resulting in reducing metro on-board flows.

In conclusion, the analysis of the Rome mobility system has been crucial to estimate the impacts of the progressive lockdown imposed by the government due to the Covid-19 epidemic. This analysis allowed to feed transport models to predict the impacts of future actions on the post-Covid mobility. Transit operators and other stakeholders are using these results to design, for example, public transport services and stations (entrances and exits) able to assure social distancing.

Further developments are still in progress. They mainly concern the predictions for the so-called "phase 3" in which the reopening of schools and universities is expected for September 2020 and it could represent a further critical point for the public transport system if social distancing will be still applied.

\section{Acknowledgements}

This paper is a revised and expanded version of the paper "Covid-19 Transport Analytics: Analysis of Rome Mobility During Coronavirus Pandemic Era" presented at the $5^{\text {th }}$ Conference on Sustainable Urban Mobility, Greece, June 17-19, 2020.

\section{References}

1. Rome Mobility Agency (Roma Servizi per la Mobilità), homepage, https://www.romamobilita.it, last accessed 2020/07/24.

2. Apple, Mobility Trends Reports, https://www.apple.com/covid19/mobility, last accessed 2020/07/24.

3. Google, COVID-19 Community Mobility Reports, https://www.google.com/covid19/mobility, last accessed 2020/07/24.

4. Moovit, Impact of Coronavirus (COVID-19) on Public Transit usage, https://moovitapp.com/insights/en/Moovit_Insights_Public_Transit_Index-countries, last accessed 2020/07/24.

5. TomTom, COVID-19 Update, https://www.tomtom.com/covid-19, last accessed 2020/07/24.

6. Cipriani, E., Gori, S., Mannini, L., Brinchi S. 2014. A procedure for urban route travel time forecast based on advanced traffic data: Case study of Rome. In: Traffic 2014 IEEE 17th International Conference on Intelligent Transportation Systems (ITSC) ITSC 2014, art. no. 6957809, pp. 936-941. DOI: 10.1109/ITSC.2014.6957809

7. Mannini, L., Cipriani, E., Crisalli, U., Gemma, A., Vaccaro, G. (2017). On-Street Parking Search Time Estimation Using FCD Data. Transportation Research Procedia. Transportation Research Procedia, Volume 27, 929-936, ISSN 2352-1465, https://doi.org/10.1016/j.trpro.2017.12.149.

8. Fusco, G., Colombaroni, C., Gemma, A., Lo Sardo, S. (2013). A quasi-dynamic traffic assignment model for large congested urban road networks. In: International Journal of Mathematical Models and Methods in Applied Sciences, 7 (4), pp. 341-349.

9. Carrese, S., Cipriani, E., Crisalli, U. Gemma, A. Mannini, L. Bluetooth Traffic Data for Urban Travel Time Forecast, 23rd EURO Working Group on Transportation Meeting, EWGT 2020, 16-18 September 2020, Paphos, Cyprus. Forthcoming.

10. Nuzzolo, A., Crisalli, U., Comi, A. and Rosati, L. (2013) An advanced pre-trip planner with personalized information on transit networks with ATIS. In: Proceedings of 16th International IEEE Conference on Intelligent Transport Systems, ITSC, The Hague, The Netherlands, pp.2146-2151.

11. Nuzzolo, A., Crisalli, U., Comi, A. and Rosati, L. (2015) DYBUS2: a real-time mesoscopic transit modeling framework. In: IEEE Proceedings of the 18th International IEEE Conference on Intelligent Transportation Systems, ITSC, Las Palmas, Spain, pp.303-308.

12. Rome Mobility Agency (Roma Servizi per la Mobilità), Covid 19: impatto sulla mobilità, https://romamobilita.it/it/covid-19-impatto-sulla-mobilita, last accessed 2020/04/18. 